\title{
Antifungal Activity of Centella asiatica on Radial Growth of Aspergillus species
}

\author{
Nasrin Akter ${ }^{1, *}{ }^{\mathbb{D}}$, Md. Abdul Hye ${ }^{1}$, Md. Nannur Rahman ${ }^{1}$ \\ 1 Department of Food Technology and Nutritional Science, Mawlana Bhashani Science and Technology University, \\ Santosh, Tangail-1902, Bangladesh \\ * Correspondence nasrinrupa.ftns@gmail.com;
}

Scopus Author ID 34879354400

Received: 21.07.2020; Revised: 9.08.2020; Accepted: 11.08.2020; Published: 15.08.2020

\begin{abstract}
The study was conducted to observe the antifungal activity of Centella asiatica against Aspergillus sp. Samples were collected from the local area of the Tangail district in Bangladesh. The bread was taken for isolating Aspergillus sp. in addition, Potato dextrose agar and malt extract agar were used as a media for culture and pure culture. One control group and two sample group $(1 \%, 5 \%)$ hydrophilic extract of $C$. asiatica has been used. The routine observation was done for a total of 5 days after 24 hours. After routine observation, it has noticed that colony diameter and number of colonies increased rapidly from day 1 to day 5 . The fungal growth was null of 5\% solution both of PDA, MEA media at the first day and these increased with rising time on $5^{\text {th }}$ days there were 1900 and 1600 respectively for black species and 1500 and 2500 respectively for green sp. Whereas compared with control group the growth was measured 1000, 1200 respectively at day 1 and these increased with rising time these numbers were 4000,4200 respectively at day 5 for black. On the other hand, at $1^{\text {st }}$ day the growth was measured 1100,1200 respectively and these increased with rising time on $5^{\text {th }}$ days there were 4200, 4300 respectively for green sp. However, at the end of the study, a remarkable change was observed between the control group and sample group after $1^{\text {st }}, 2^{\text {nd }}, 3^{\text {rd }}, 4^{\text {th }}$ and $5^{\text {th }}$ days. Finally, the study showed that the bioactive compounds of $C$. asiatica are a potential source of preservative that inhibits the growth of fungus.
\end{abstract}

Keywords: Antimicrobial activity; Antifungal activity, Preservatives; Centella asiatica; Aspergillus $s p$; Extraction.

Abbreviation: PDA=Potato Dextrose Agar; MEA= Malt Extract Agar; C.asiatica $=$ Centella asiatica; Aspergillus $s p=$ Aspergillus species. (c) 2020 by the authors. This article is an open-access article distributed under the terms and conditions of the Creative
Commons Attribution (CC BY) license (https://creativecommons.org/licenses/by/4.0/).

\section{Introduction}

Antimicrobial agents are chemical compounds used as additives for food preparation that retard the microbial growth or destroy the microbes. During harvesting and processing time, a certain amount (40\%) of food loss occurred in developing countries [1]. Benzoate, sorbate, nitrite, and nitrate are common chemical preservatives that are used to reduce or destroy the fungal growth [2]. There are some harmful effects of these chemicals and have been suspected of causing allergies, asthma, and skin rashes. That's why consumers feel doubt about the safety of chemical preservatives, and now they give more attention to natural origins like Spices and herbs. Detection of food contamination is of major significance and concern in areas like healthcare, agriculture, beverage, and fermentation industries. By the emergence of technologies, uses of chemical preservatives are declined day by day and increasing the use of 
natural preservatives [3]. Plants are the most important source of chemical compounds, and it has an antimicrobial and antifungal property which found in leaves, root, stem, bark, etc. [4]. Being situated in the tropics, Bangladesh has rich in biodiversity that's why for a long time, a huge number of plants are being used in the medical history and also used as a control of fungal diseases. Sustainable development has emerged as a new paradigm of development to maintain the human-ecosystem equilibrium from the last 40 years, and an example of sustainable development is $C$. asiatica [5].

Plants contribute to $75 \%$ of molecular medicines (MM) either directly or indirectly[6]. Centella asiatica is a medicinal plant native to the wetlands in several Southeast Asian countries, and it is also available in Bangladesh. For centuries $C$. asiatica work against infections and diseases, including eczema, Ulcer, diarrhea, fever, and respiratory infections [7]. The purified extract of $C$. asiatica leaves significantly higher amounts of centellosides and antiglycation properties [8]. In addition, for com $\neg$ plementary therapy of vascular conditions, its extract works as a suitable intervention [9]. Moreover, the extracts of $C$. asiatica may help regenerate collagen and elastin, and $C$. asiatica cream may be a valuable option for the treatment of stretch marks in the postpartum period for women [10].

C. asiatica has antimicrobial activity that inhibited fungal growth and reduces food loss. It has also be used for many purposes such as antibacterial, anticancer, and antioxidant. The leaf juice is used as a good health tonic and also gives relief from hypertension, CNS, and gastrointestinal disease [11]. Zheng et al. [12] revealed that $C$. asiatica has an anti-depressive sedative effect. Therefore, the present investigation attempts to isolate and investigate the antimicrobial activities of $C$. asiatica extracts. In the food technology and food industry, the use of Centella asiatica in food and beverages has increased over the years, basically due to its beneficial functional properties [13]. The primary objective of this paper is to evaluate the preservative action of a hydrophilic extract of $C$. asiatica against Aspergillus species.

\section{Materials and Methods}

\subsection{Sample collection.}

This research was held from January 2019 to June in the laboratory of the Department of Food Technology and Nutritional Science. The plant of $C$. asiatica was collected from the area of University campus, Tangail, Dhaka, Bangladesh.

\subsection{Preparation of C. asiatica extract.}

Samples (Leaf) were collected from plants and cleaned deionized-distilled water to remove sand and any kind of dirty material. Then, Samples were placed in an aluminum foil and treated at $-20^{\circ} \mathrm{C}$ for 24 hours. After that, samples were given in freeze drier for 3 days at $45^{\circ} \mathrm{C}$. Moreover, the samples were then ground and stored in air-tight containers at $4^{\circ} \mathrm{C}$ until further analysis. The powder of Centella asiatica was weighted with the electric balance and transferred into separate $100 \mathrm{ml}$ conical flasks.

\subsection{Preparation of agar plate.}

Potato Dextrose Agar (PDA) and malt extract agar (MEA) were used in this study as a medium for fungal growth. Potato Dextrose Agar and Malt extract agar were prepared by adding $1.95 \mathrm{~g}$ of commercial PDA powder and $2.5 \mathrm{~g}$ of MEA powder in 50ml distilled water. 
$1 \%$ and 5\% hydrophilic extract of Centella asiatica were mixed in solution. The mixture was dissolved and subsequently autoclaved for $15 \mathrm{~min}$ at $121^{\circ} \mathrm{C}$. The cooling media was poured into the Petri dish and left hardened for $24 \mathrm{~h}$ before used.

\subsection{Preparation of culture and pure culture.}

Aspergillus $s p$. was cultured on PDA and MEA by adding spore suspension and then kept at $37{ }^{\circ} \mathrm{C}$ in the incubator for 48 hours to estimate the radial growth of strains. Isolation of a pure culture may be enhanced by providing a mixed inoculum with a medium favoring the growth of one organism to the exclusion of others. The purpose of pure culture is to separate cells of mixed culture and compare growth characteristics beneath and on the surface of the agar. After pure culture, two types of species (Black, Green) were separated.

\subsection{Measurement of diameter and microbial growth.}

At the beginning of the incubation period, the diameter of the colony was too small in size but increasing with day time, they increase their size, and in the end, all analogs were completely colonized. To analyze the preservative effect of fungal growth, the most appropriate method is a direct measure of colony diameter. However, it is time-consuming, the best one for research purposes. The count was recorded in colony-forming units per $\mathrm{ml}(\mathrm{CFU})$. Mile and Misra are the most effective method to calculated CFU, and it is a fruitful way to determine microbial load; it is useful to determine the microbial load.

\section{Results and Discussion}

\subsection{Results.}

For testing the antifungal effect of $C$. asiatica, different solutions were taken separately on the sterilized Petri dishes with the help of a sterilized pipette. The Petri dishes were marked as 0 (control), 1 ( $1 \%$ solution), 2 (5\% solution). When media solidified, the Petri plates were inoculated at the center of the media with mycelium disc of the test fungus taken from the pure old culture. The whole set up was incubated in an inverted position at $33^{\circ} \mathrm{C}$ incubator for 5 days. The diameter and radial growth of Aspergillus $s p$. was measured after $1^{\text {st }}, 2^{\text {nd }}, 3^{\text {rd }}, 4^{\text {th, }}$ and $5^{\text {th }}$ days at 24 hours of the time interval.

For the media of PDA, the diameter of fungal growth (Black) was measured for the control group was $1.5(\mathrm{~cm} / \mathrm{CFU})$ and a number of fungal was 1000 at $1^{\text {st }}$ day, and it increased gradually with rising time on 5 days, and the diameter was $4.7(\mathrm{~cm} / \mathrm{CFU})$, and the number of microbial was 5000. On the other hand, when used $1 \%$ and $5 \%$ concentration the diameter of fungal growth was measured $0.55,0(\mathrm{~cm} / \mathrm{cfu})$ respectively and a number of microbial were 600,0 at $1^{\text {st }}$ day and it's increased gradually on $5^{\text {th }}$ days, and the diameter values were $3.6,0.6$ $(\mathrm{cm} / \mathrm{CFU})$ respectively and the number of microbial were 2900 and 1900 respectively.

For MEA media, the diameter of fungal growth measured for the control group was1.56 (cm/CFU), and the number of microbial was 1200 at $1^{\text {st }}$ day, and it increased on $5^{\text {th }}$ days, and the diameter was $4.72(\mathrm{~cm} / \mathrm{CFU})$, and the number of microbial was 4200 . On the other hand, when used $1 \%$ and $5 \%$ concentration the diameter of fungal growth was measured $0.56,0$ $(\mathrm{cm} / \mathrm{CFU})$ respectively and a number of microbial were 800,0 at $1^{\text {st }}$ and it increased gradually on 5 days and the diameter was 2,15, $1.25(\mathrm{~cm} / \mathrm{CFU})$ respectively and a number of microbial 
3000 and 1600 respectively. The diameter and Fungal growth profile of $C$. asiatica on Aspergillus sp (Black) are shown in Figures 1 and 2.

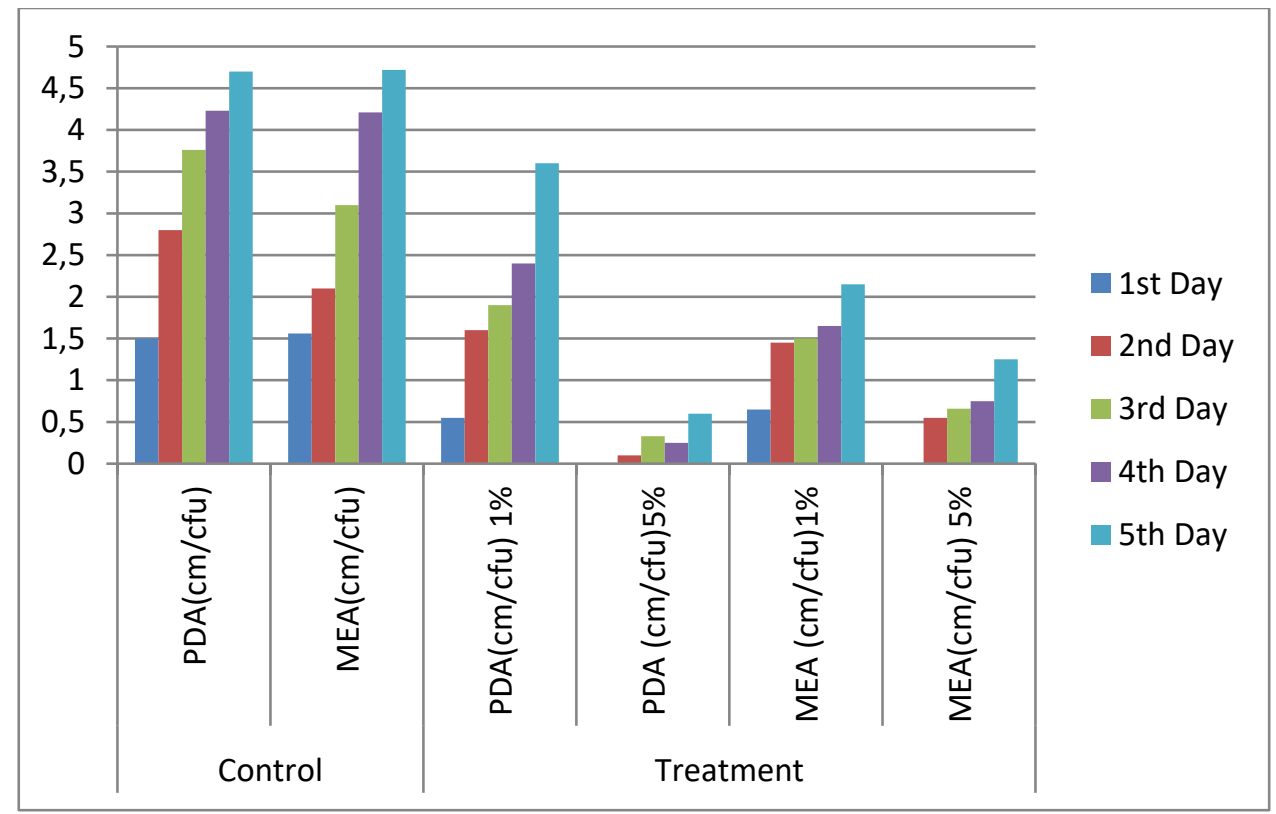

Figure 1. The diameter of Aspergillus sp. (Black) colony on C. asiatica.

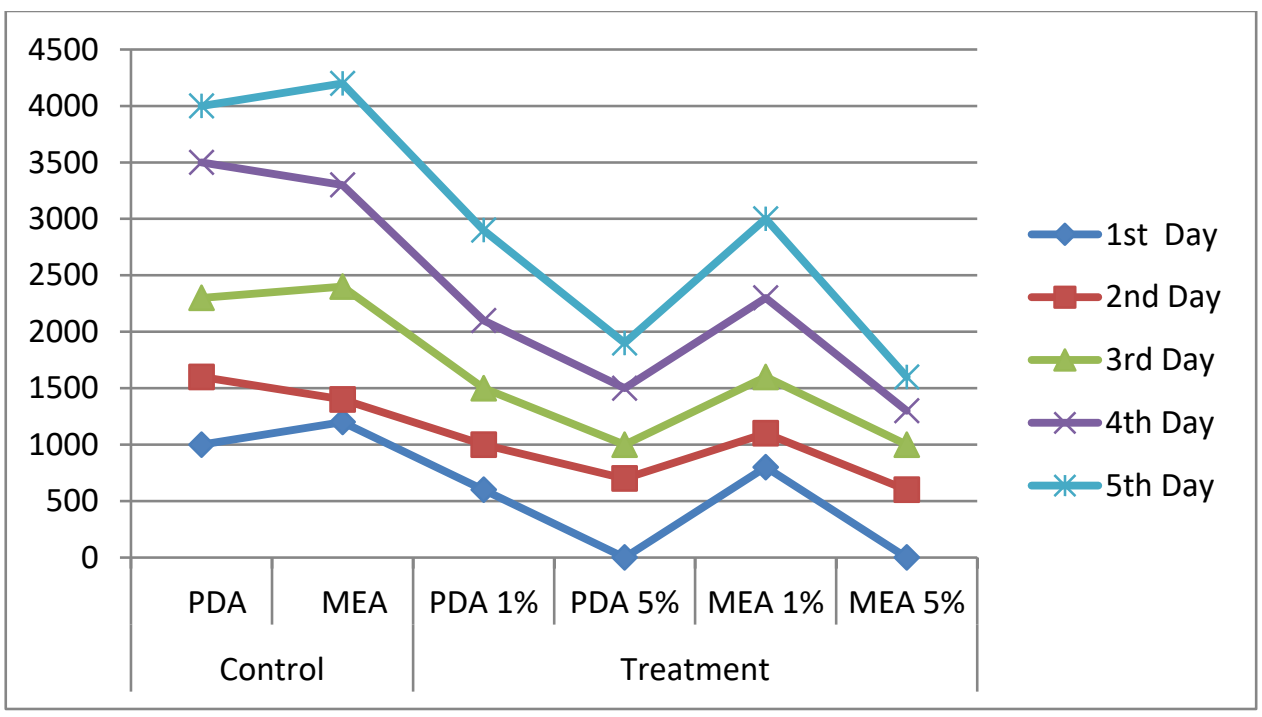

Figure 2. Fungal growth profile of C. asiatica on Aspergillus sp. (Black).

The diameter and radial growth of Aspergillus sp. (Green) were measured after $1^{\text {st }}, 2^{\text {nd }}$, $3^{\text {rd }}, 4^{\text {th, }}$ and $5^{\text {th }}$ at 24 hours of the time interval. For the media of PDA the diameter of fungal growth for the control group was1.41 (cm/CFU), and the number of microbial was 1100 at $1^{\text {st }}$ day, and it increased gradually on $5^{\text {th }}$ days, and the diameter was $4.5(\mathrm{~cm} / \mathrm{CFU})$, and the number of microbial was 4200 . On the other hand, when used $1 \%$ and $5 \%$ concentration, the diameter of fungal growth was 3.4, 0.62 (cm/CFU), respectively, and the number of microbial 2800 and 1500 respectively after 5 days. For MEA media, the diameter of fungal growth measured for the control group was $1.5(\mathrm{~cm} / \mathrm{CFU})$, and the number of microbial was 1200 at $1^{\text {st }}$ day, and it's increased gradually on $5^{\text {th }}$ days, and the diameter was $4.7(\mathrm{~cm} / \mathrm{CFU})$, and the number of microbial was 4300 . On the other hand, when used $1 \%$ and $5 \%$ concentration, the diameter values were 2.15, 1.37 (cm/CFU), respectively, and the number of microbial 2900 and 2500 respectively after 5 days. The diameter and Fungal growth profile of $C$. asiatica on Aspergillus $s p$ (Green) are shown in Figures 3 and 4. 


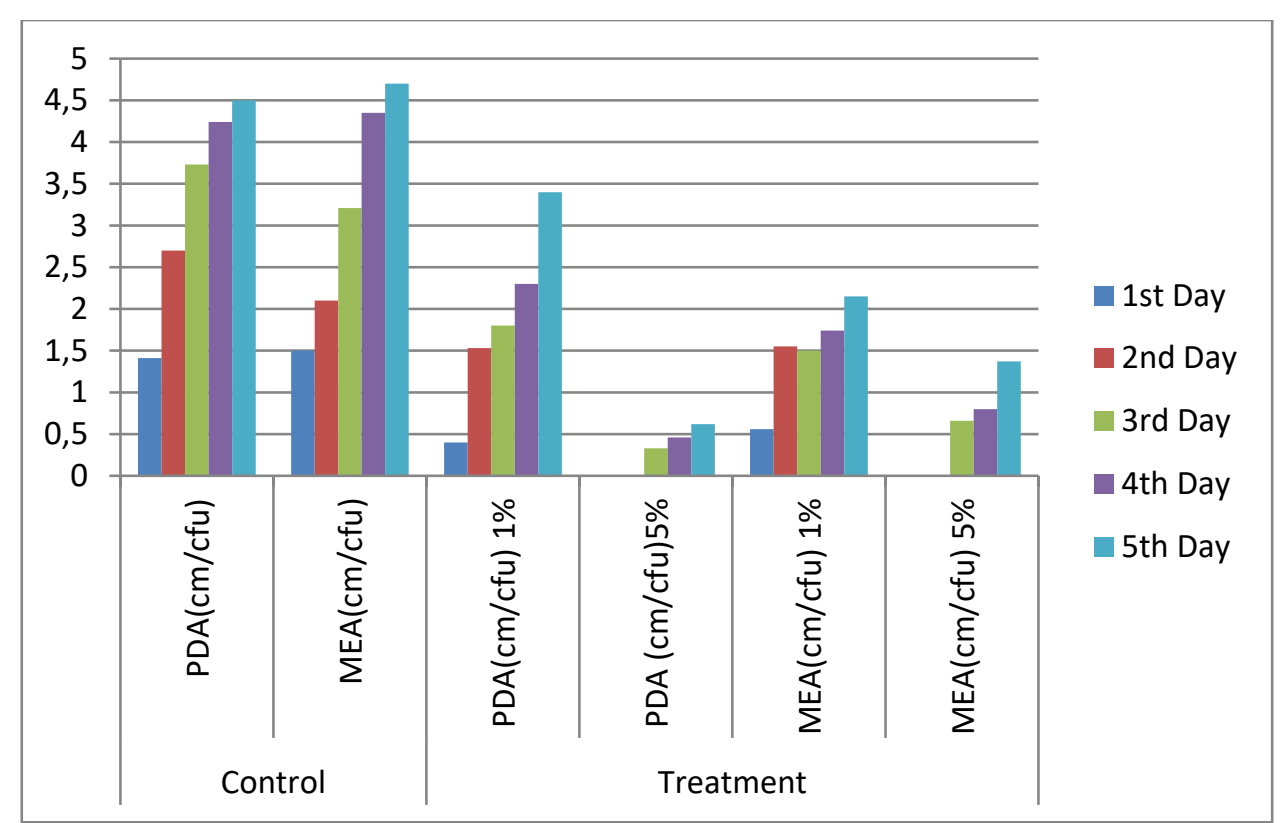

Figure 3. Diameter of Aspergillus sp. (Green) colony C. asiatica.

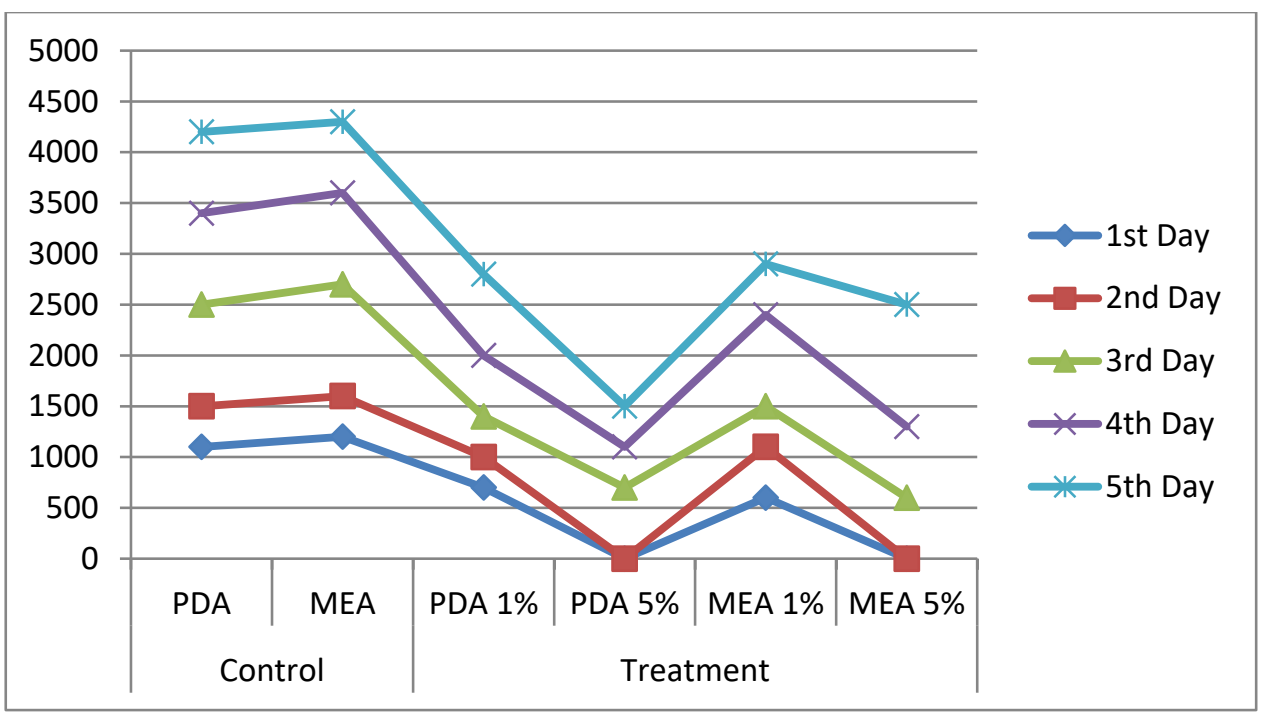

Figure 4. Fungal growth profile of C. asiatica on Aspergillus sp.

\subsection{Discussion.}

The present study showed that extracts of $C$. asiatica had been determined against different microorganisms, $A$. niger. The extracts of $C$. asiatica showed a significant preservative effect against $A$. niger at $5 \%$ and $1 \%$ solution. In these findings, $5 \%$ extracts showed a maximum inhibitory effect than the control group and $1 \%$ solution. These findings are similar to Ismail et al. [14] showed that the antimicrobial effects of Centella extract on food, specifically on fish surimi and reveal that Centella extract could inhibit the microbial growth on fish surimi. According to Dash et al. [15], different extracts of $C$. asiatica showed antifungal and antibacterial activity and among all extract ethanol extract was most effective to inhibit the microbial growth especially A. niger and B. subtilis and Idris and Nadzir [16] showed that $C$. asiatica extracts can inhibit the growth of $B$. subtilis and $A$. niger and which further can be developed into an alternative to synthetic antimicrobials. $C$. asiatica has effective antihypertensive, nootropic, neuroprotective, cardioprotective, antimicrobial, and anticancer activities in preclinical studies [17]. Nasution et al. [18] depicted that C. asiatica root demonstrated a strong inhibitory effect than the leaf. Prakash et al. [19] observed that 
petroleum ether, ethanol, chloroform, n-hexane, and aqueous extract of $C$. asiatica showed activity against Aspergillus niger and $C$. albicans with a zone of inhibition of 14, 16, 13, 13, and $11 \mathrm{~mm}$ and 13,15, 15,11, and $9 \mathrm{~mm}$ respectively. Centella asiatica is a medicinal plant, and it could be a potential source for bioactive compounds [20]. Mamtha et al. [21] found that the antimicrobial effect of $C$. asiatica against the enteropathogens and it acts as an antidiarrheal drug. According to Zhang et al. [22] Hibiscus sabdariffa, Centella asiatica, Moringa oleifera, and Murraya koenigii leaves extract works against Listeria monocytogenes, Salmonella typhimurium, and E. coli O157:H7 because these leaves have antioxidant activity and as antimicrobial agents with potential medicinal value and can be used as potential sources of vitamins, minerals and phenolic compounds.

\section{Conclusions}

The purpose of this research was to overlook the preservative effect of $C$. asiatica against Aspergillus sp. Fungi have a detrimental effect, and for this reason, a large amount of food is lost every year. Although chemical preservatives are used to reduce this loss, it has some side effect. But due to the presence of wide bioactive compounds, different kinds of plants are used, which led to inhibit the growth of microorganisms. Plants (organ herbs) include $C$. asiatica and have an effective antifungal and antibacterial effect. This study showed that if a hydrophilic extract of $C$. asiatica can be used at different concentrations, it can reduce or inhibit the fungal growth in food products, especially in bakery products. To conclude, further research is needed to know the exact mechanism of $C$. asiatica extract and their preservative action on food as a preservative.

\section{Funding}

This research received no external funding.

\section{Acknowledgments}

The authors are grateful who have participated in this research work.

\section{Conflicts of Interest}

The authors declare no conflict of interest.

\section{References}

1. FAO. Food Loss and Waste in Developing Countries. Volume 10. 2018.

2. Silva, M.M.; Lidon, F.C. An overview on applications and side effects of antioxidant food additives. Emirates Journal of Food and Agriculture 2016, 823-832, https://doi.org/10.9755/ejfa.2016-04-351.

3. Aneja, K.R.; Dhiman, R.; Aggarwal, N.K.; Aneja, A. Emerging Preservation Techniques for Controlling Spoilage and Pathogenic Microorganisms in Fruit Juices. International Journal of Microbiology 2014, 2014,14, https://doi.org/10.1155/2014/758942.

4. Bariş, Ö.; Güllüce, M.; Sahin, F.; Ozer, H.; Kiliç, H.; Özkan, H.; Sökmen, M.; Özbek, T. Biological activities of the essential oil and methanol extract of Achillea biebersteinii Afan. (Asteraceae). Turkish Journal of Biology 2006, 30, 65-73.

5. Bo, L.; Iguera, R. Centella asiatica: an example of sustainable development. Esperienze Dermatol 2018, 20, 38-9, https://doi.org/10.23736/S1128-9155.18.00467-3.

6. Rani, K.; Tyagi, M; Singh, A; Shanmugam, V; Shanmugam, A; Pillai, M; Srinivasan, A. Identification of annotated metabolites in the extract of Centella asiatica. Journal of Medicinal Plants Research 2019, 13, 112-128, https://doi.org/10.5897/JMPR2018.671. 
7. Togni, S.; Maramaldi, G.; Franceschi, F.; Riva, A. Eggenhoffner, R and Giacomelli, L. Centella asiatica: an old herbal cure with new potential ap 7 plications. Esperienze Dermatol 2018, 20, 4-8, https://doi.org/10.23736/S1128-9155.18.00457-0.

8. Nasution, M.Y.; Restuati, M.; Pulungan, A.S.S.; Pratiwi, N.; Diningrat, D.S. Antimicrobial Activities of Centella asiatica Leaf and Root Extracts on Selected Pathogenic Micro-organisms. Journal of Medical Sciences 2018, 18, 198-204, https://doi.org/10.3923/jms.2018.198.204.

9. Belcaro, G.; Hosoi, M.; Hu, S.; Dugall, M.; Feragalli, B.; Cotellese, R. Centella asiatica: new microcirculatory and vascular application in preventive and clinical medicine. Esperienze Dermatol 2018, 20, 9-11, https://doi.org/10.23736/S1128-9155.18.00464-8.

10. Togni, S.; Maramaldi, G.; Pagin, I.; Riva, A.; Eggenhoffner, R.; Giacomelli, L.; Cesarone, M.R.; Belcaro, G. Postpartum stretch marks treated with Centella asiatica cream: report of efficacy from a pilot registry study. Esperienze Dermatol 2018, 20, 23-6, https://doi.org/10.23736/S1128-9155.18.00460-0.

11. Kant, R.; Srivastav, P. P; Datta, A. K.. The Medicinal Role of Centella asiatica and Its Applications in the Dahi: A Research Review. Journal of Pharmaceutical Research International 2019, 1-9, https://doi.org/10.9734/jpri/2019/v28i630220.

12. Zheng, C.J.; Qin, L.P. Chemical components of Centella asiatica and their bioactivities. Zhong Xi Yi Jie He Хие Bao 2007, 5, 348-351, https://doi.org/10.3736/jcim20070324.

13. Jhansi D and Dr. Manjula Kola. The antioxidant potential of Centella asiatica: A review. Journal of Medicinal Plants Studies 2019, 7, 18-20.

14. Ismail, S.N.; Ismail, Z.; Nordin, N. Antimicrobial Effect of Centella asiatica Extract On Fish Surimi. Politeknik \& Kolej Komuniti Journal of Engineering and Technology 2016, 1. http://103.8.145.246/index.php/PMJET/article/view/1174.

15. Das, A.J. Review on Nutritional, Medicinal and Pharmacological Properties of Centella asiatica (Indian pennywort). Journal of Biologically Active Products from Nature 2011, 1, 216-228, https://doi.org/10.1080/22311866.2011.10719089.

16. Mohd Nadzir, M.; Idris, F. Antimicrobial activity of centella asiatica on aspergillus niger and bacillus subtilis. Chemical Engineering Transactions 2017, 56, 1381-1386, https://doi.org/10.3303/CET1756231.

17. Nagoor Meeran, M. F; Goyal, S. N; Suchal, K., Sharma, C; Patil, C. R; Ojha, S. K. Pharmacological properties, molecular mechanisms, and pharmaceutical development of asiatic acid: a pentacyclic triterpenoid of therapeutic promise. Frontiers in pharmacology 2018, 9, 892, https://doi.org/10.3389/fphar.2018.00892.

18. Nasution, M.Y.; Restuati, M.; Pulungan, A.S.S.; Pratiwi, N.; Diningrat, D.S. Antimicrobial Activities of Centella asiatica Leaf and Root Extracts on Selected Pathogenic Micro-organisms. Journal of Medical Sciences 2018, 18, 198-204, https://doi.org/10.3923/jms.2018.198.204.

19. Prakash, V.; Jaiswal, N.I.S.H.I.T.A.; Srivastava, M.R.I.N.A.L. A review on medicinal properties of Centella asiatica. Asian J Pharm Clin Res 2017, 10, 69, http://dx.doi.org/10.22159/ajpcr.2017.v10i10.20760.

20. Devi, N.N.; Prabakaran, J.J. Bioactive metabolites from an endophytic fungus Penicillium sp. isolated from Centella asiatica. Curr Res Environ Appl Mycol 2014, 4, 34-43, https://doi.org/10.5943/CREAM/4/1/3.

21. Mamtha, B.; Kavitha, K.; Srinivasan, K.K.; Shivananda, P.G. An in vitro study of the effect of Centella asiatica [Indian pennywort] on enteric pathogens. Indian Journal of Pharmacology 2004, 36, 41, http://www.ijp-online.com/text.asp?2004/36/1/41/6793.

22. Zhang, M.; Hettiarachchy, N.S.; Horax, R.; Kannan, A.; Praisoody, A.; Muhundan, A. Phytochemicals, antioxidant and antimicrobial activity of Hibiscus sabdariffa, Centella asiatica, Moringa oleifera and Murraya koenigii leaves. Journal of Medicinal Plants Research 2011, 5, 6672-6680, https://doi.org/10.5897/JMPR11.621. 